\title{
Numerical investigation of dynamic response of a rockbolt under drop testing and simulated seismic loading conditions
}

\author{
P Zhang Luleå University of Technology, Sweden \\ E Nordlund Luleå University of Technology, Sweden
}

\begin{abstract}
When designing rockbolts for rockburst conditions, it is commonly assumed that the kinetic energy of an ejected rock block is absorbed by rockbolts. To obtain the energy absorption capacity of a rockbolt, drop testing has been widely used. The advantage of using a drop test to investigate the dynamic performance of rockbolts is that it can provide repeatable results. However, it is recognised that the drop test technique is a crude simulation of an actual seismic loading mechanism. To investigate the difference, numerical models were constructed to simulate the response of a rockbolt under both drop testing and simulated seismic loading conditions using the numerical code UDEC (Universal Distinct Element Code, Ver 6.0) (Itasca Consulting Group 2018). The seismic wave is simplified as a full cycle sinusoidal wave which generates the same ejection velocity magnitude on a reinforced rock block as the drop test. The rockbolt was found to fail under the simulated seismic loading condition but survived the drop test. This difference is because reflected seismic waves create additional displacement between the ejected rock block and adjacent rock block. The results indicate that impact energy or kinetic energy should be used carefully when determining the dynamic demand on rockbolts as it does not consider the critical interaction between seismic waves and the reinforced rock blocks. Additional parameter sensitivity studies showed how the frequency of a simulated seismic wave affects the dynamic response of rockbolts. The results can be used to improve our understanding on the dynamic response characteristics of ground support. The knowledge gained from the comparison can be used to improve the estimation of dynamic demand on rockbolts under rockburst conditions.
\end{abstract}

Keywords: drop test, seismic loading, dynamic response, rockbolt, numerical simulation

\section{Introduction}

When designing rockbolts for rockburst conditions, it is commonly assumed that the kinetic energy of an ejected rock block is absorbed by the bolts. To obtain the energy absorption capacity of a rockbolt, physical testing has been performed over the past half century, using blasting and drop weight impacts to represent the dynamics of rockburst loading. Both testing methods have their disadvantages and the details can be found in Hadjigeorgiou \& Potvin (2007) and Stacey (2012).

However, as drop weight testing is relatively simple and quick to perform and can provide repeatable results, it is still widely used for estimating the energy absorption capacity of rockbolts and for comparative and quality control purposes (Stacey 2012; Li et al. 2014). Currently, there are two drop testing methods available for testing the energy absorption capacity of rockbolts. In both cases a split tube configuration is usually adopted, with the bolt encapsulated in the tubes with grout (Li et al. 2014). The first testing method is called direct impact method. In this method, a mass freely falls onto an impact plate attached to the lower tube while the upper tube is fixed. Kinetic energy is transferred to the bolt via the plate and the lower tube. The most well-known test facility is located at Canada Centre for Mineral and Energy Technology (CanMet) in Ottawa, Canada (Plouffe et al. 2008) and a newly developed one is housed at New Concept Mining premises in Johannesburg, South Africa (Bosman et al. 2018). The second drop testing method uses the momentum transfer concept. In this method, the mass and split tubes fall freely together until the stopper at the upper end of the split tubes meets a stationary beam. The movement of the assembly is then stopped, with the momentum and kinetic energy transferred to the bolt via the plate and the lower tube. The first test facility 
with this capability is located in Western Australia at the Western Australian School of Mines (Player et al. 2008) and a newly manufactured one based on the same concept has been built at Swerea MEFOS AB, Luleå, Sweden (Sandberg 2017).

This demonstrates that people continue to develop and improve drop test capabilities to provide comparable test results of different bolt products and to investigate the dynamic capacity of rockbolts under seismic loading conditions. Recent test results found that the dynamic capacity of a rockbolt is not a constant value and the manner in which a rockbolt is loaded will affect its dynamic capacity (Bosman et al. 2018). As impact loading from drop tests may not be representative of rockburst loading, it is worth investigating the effects of different loading conditions (drop test loading and seismic loading) on the response of rockbolts and to further improve the application of test results to an actual rockburst environment.

Therefore, a number of conceptual numerical models were constructed to simulate the response of a fully grouted rebar under both drop testing and simulated seismic loading conditions using the numerical code UDEC (Universal Distinct Element Code, Ver 6.0) (Itasca Consulting Group 2018). The rockbolt parameters were first calibrated using experimental results from static pull-out tests. After that, the rockbolt together with two rock blocks was loaded dynamically under drop testing and simulated seismic loading conditions. For comparison purpose, the model geometry, boundary conditions and material properties were kept as similar as possible between drop testing and seismic loading except for the dynamic loading pattern. As the focus of the paper is to investigate the difference between different loading conditions, the models were not designed to replicate any of the reported drop tests in detail, but their general loading conditions.

\section{$2 \quad$ Numerical modelling}

\subsection{Modelling methodology}

A two-dimensional numerical code, UDEC (Itasca Consulting Group 2018), was used in this study. The reason UDEC was chosen for this investigation is because UDEC is able to simulate discontinuous opening and separation between discrete blocks under static and dynamic loading conditions, and the rockbolt element can consider complex interaction between bolt and rock mass.

As the momentum transfer concept introduced by Player et al. (2008) seems to provide more realistic loading than the direct impact drop test considering the interaction of seismic wave and rock mass near an excavation. The second drop testing method using the momentum transfer concept was thus chosen for this numerical investigation.

The numerical models were not designed to replicate any of the reported drop tests in detail, e.g. damper, loading frame, but the general loading conditions, and hence the model geometry, boundary conditions and material properties from the actual drop test were slightly modified to keep the same as the simulated seismic loading condition.

\subsection{Model description}

The general configuration of the UDEC models for both simulated seismic loading and drop testing is schematically shown in Figure 1. When simulating seismic loading, a long, elastic rock bar with a length of $200 \mathrm{~m}$ and a width of $1 \mathrm{~m}$ was used to avoid wave reflection from the top boundary. For comparison purposes, the same dimension was used for drop testing simulation, even though the dimension of tested samples for actual drop test is much shorter and smaller. A joint was used to divide the model into two blocks, upper block and lower block, which makes the lower block subjected to moving independently from the upper block. The joint was located $0.5 \mathrm{~m}$ from the bottom boundary assuming the depth of an ejected rock is $0.5 \mathrm{~m}$. The joint was simulated as a planar and closed fracture/contact with infinite high stiffness and zero tensile and shear strength in the numerical models. A fully grouted rebar with a length of $3.0 \mathrm{~m}$ and diameter of $20 \mathrm{~mm}$ was used in this simulation which intersects the joint at right angles. The mechanical parameters for the rebar and the joint are presented in Tables 1 and 2, respectively. 


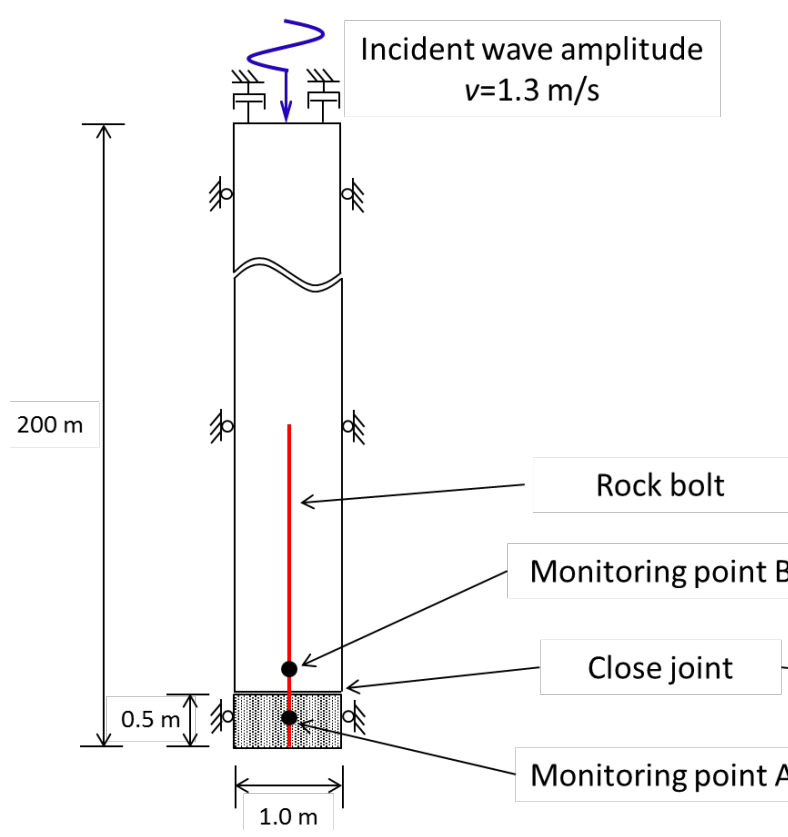

(a)

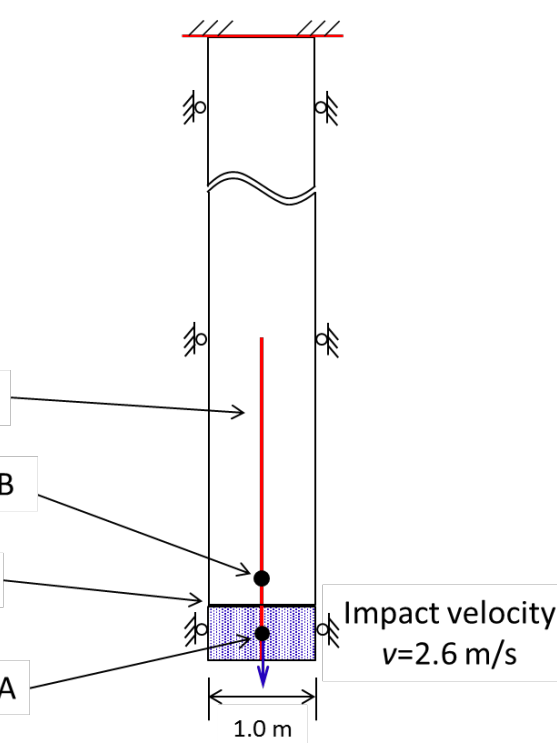

(b)

Figure 1 Schematic diagram of the numerical model (not to scale) under (a) simulated seismic loading, and (b) drop testing

Table $1 \quad$ Parameters for rock block and rockbolt

\begin{tabular}{llll}
\hline & Young's modulus (GPa) & Poisson's ratio & Density $\left(\mathrm{kg} / \mathrm{m}^{3}\right)$ \\
\hline Rock block & 70 & 0.27 & 2,800 \\
Fully grouted rebar & 200 & 0.2 & 7,800 \\
\hline
\end{tabular}

Table 2 Parameters for joint

\begin{tabular}{lllll}
\hline $\begin{array}{l}\text { Normal stiffness } \\
(\mathrm{GPa} / \mathrm{m})\end{array}$ & $\begin{array}{l}\text { Shear stiffness } \\
(\mathrm{GPa} / \mathrm{m})\end{array}$ & $\begin{array}{l}\text { Tensile strength } \\
(\mathrm{MPa})\end{array}$ & $\begin{array}{l}\text { Cohesion } \\
(\mathrm{MPa})\end{array}$ & $\begin{array}{l}\text { Friction angle } \\
\text { (degree) }\end{array}$ \\
\hline 10,000 & 10,000 & 0 & 0 & 0 \\
\hline
\end{tabular}

To simulate the interaction between a rockbolt and a rock mass, rock material instead of grout as often used in the split tube of the drop test, was adopted in the numerical models. The properties of the rock material are from LKAB's Kiirunavaara underground mine (Malmgren \& Nordlund 2008) and are listed in Table 1.

\subsubsection{Seismic loading}

When a drop test is conducted, a P-wave is generated along the axis of a rockbolt and further creates elongation of the rockbolt or ejection of the rock block if the rockbolt fails. To compare seismic loading with the drop test loading, an incident P-wave was generated by applying a dynamic load normally on the top boundary of the rock bar and the seismic wave propagated through the model in a vertical $(y)$ direction. A non-reflecting boundary was placed at the top boundary to avoid wave reflections from the artificial boundary. The bottom boundary was free of restraint to simulate the free surface. Because the incident wave was a P-wave, displacements in the $x$-direction of the left and right boundaries were restricted.

Field measurement of ground motion near an excavation surface was obtained through a field monitoring program (Zhang et al. 2016). A waveform was recorded in a triaxial geophone located at $0.4 \mathrm{~m}$ depth from the excavation surface (Figure 2). By looking at the waveform, a simplified sinusoidal seismic wave was assumed and used in the modelling. Based on several trial analyses, a velocity amplitude of $1.3 \mathrm{~m} / \mathrm{s}$ for the 
incident seismic wave was determined which generated an ejection velocity of around $2.6 \mathrm{~m} / \mathrm{s}$ at the ejected rock block because of wave reflection and superposition near the free surface. The effect of wave frequency on the rockbolt response was also investigated by using the seismic loading model.

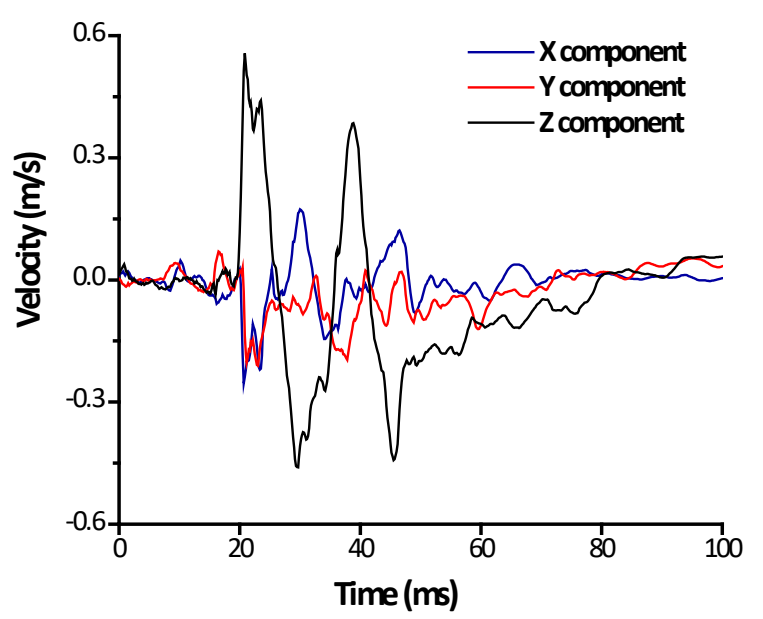

Figure 2 Waveform recorded in a triaxial geophone located $0.4 \mathrm{~m}$ far away from the excavation surface in the roof from a Swedish underground mine from an actual seismic event on 11 February, 2017

\subsubsection{Drop testing}

In the drop testing model, the rock bar has the same dimension and material properties as in the seismic loading model. The rock bar is also divided into an upper and a lower block due to the existing joint.

In the actual drop test, the movement of the upper block is stopped due to the usage of the stopper or damper. As the arresting mechanism of a damper is complex and the detail is unclear from the laboratory tests, the top boundary was fixed and the upper block was simulated as a stationary block for simplification. To make the results between the drop test and seismic loading test comparable, a constant velocity of $2.6 \mathrm{~m} / \mathrm{s}$ was applied at the lower block in the drop test model which makes the velocity of the lower block in both models equal.

Two monitoring points were placed in the numerical models to measure the particle velocities and displacements. They were located at $0.25 \mathrm{~m}$ above (Point $\mathrm{B}$ ) and below (Point A) the joint, respectively. The displacement at the joint between the upper block and the lower block of the models and the load in the rockbolt at the joint were recorded by using FISH programming.

\subsection{Parameter calibration for rockbolt}

The rockbolt element in UDEC was used to simulate the response of a fully grouted rebar. The rockbolt element is a 2D element with three degrees of freedom (two displacements and one rotation) at each end node. It can provide bending resistant behaviour, can yield in the axial direction, and can also simulate bolt breakage based upon a user-defined tensile failure strain limit. Rockbolt elements interact with rock material via shear and normal coupling springs. The coupling springs are non-linear connectors that transfer forces and motion between the rockbolt elements and the grid points associated with the block zone in which the rockbolt nodes are located. The behaviour of the shear coupling springs is identical to the representation for the shear behaviour of grout in the borehole between rock and rebar. The normal coupling springs are primarily intended to simulate the effect of the medium squeezing around the rockbolt. The detailed formulation of rockbolt elements can be found in the UDEC manual (Itasca Consulting Group 2018).

The rockbolt parameters have been calibrated to reproduce the behaviour of a fully grouted rebar in a pull-out test. The pull-out experimental results used as a reference for this calibration are from Stjern (1995). The pull-out tests were conducted by a test rig specially constructed for bolt testing (Figure $3 \mathrm{a}$ ). The rock mass was simulated by two high strength concrete cubic blocks, which could be moved both lateral and 
normal to the joint plane between the two blocks. The rock blocks had the dimension of $0.95 \mathrm{~m} \times 0.95 \mathrm{~m} \times$ $0.95 \mathrm{~m}$. Bolt holes with the diameter of $28 \mathrm{~mm}$ were drilled in the blocks with percussive drilling. The bolts had a diameter of $20 \mathrm{~mm}$ and were installed with resin grouting according to the normal field installation practice. During the test, one of the concrete blocks was fixed, and the other one was pulled along the bolt axis by two hydraulic cylinders. The displacement of the stretched section was measured at the joint of the two blocks and the force in the rockbolt was measured by a load cell at the collar. The force-displacement curves obtained from the laboratory tests are presented in Figure $3 \mathrm{~b}$.

The calibrated properties for the tested rebar in rockbolt element used in UDEC are presented in Table 3. The force-displacement curve obtained from the numerical simulation is shown as a red line in Figure $3 \mathrm{~b}$. As commonly observed during the experimental tests, the curve can be divided into three stages: elastic, yielding and rupture stage. First, the force increases with the increase of the displacement at the joint until it reaches the load-carrying capacity $(157 \mathrm{kN})$ of the bolt. There is non-linear deformation at the initial loading stage, which might be attributed to the interaction of rock blocks and rebar. During the yielding stage, the force in the bolt is constant but the displacement continues to increase. When the total displacement reaches $33 \mathrm{~mm}$, the bolt fails and the force drops to zero. The simulation provides a simplified force-displacement characteristic of the rebar as the strain hardening stage was not considered. However, the result is considered to be relatively reliable and reasonable comparing the modelling and experimental curves. It can be concluded that the UDEC bolt model could be used to reproduce the force-displacement characteristics of the rebar under axial loading condition.

Table 3 Calibrated parameters for the tested rebar in rockbolt element used in UDEC

\begin{tabular}{lll}
\hline Tensile yield load & $\mathrm{kN}$ & 157 \\
Stiffness of shear coupling spring & $\mathrm{N} / \mathrm{m} / \mathrm{m}$ & $6 \times 10^{7}$ \\
Cohesive strength of the shear coupling spring & $\mathrm{N} / \mathrm{m}$ & $1.068 \times 10^{6}$ \\
Stiffness of normal coupling spring & $\mathrm{N} / \mathrm{m} / \mathrm{m}$ & $1 \times 10^{9}$ \\
Cohesive (and tensile) strength of normal coupling spring & $\mathrm{N} / \mathrm{m}$ & $1 \times 10^{9}$ \\
Tensile failure strain limit & $\%$ & 35 \\
\hline
\end{tabular}

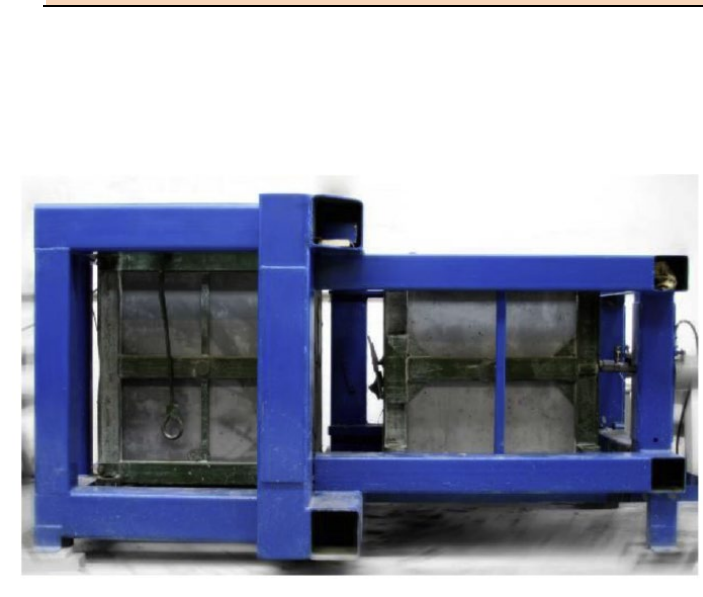

(a)

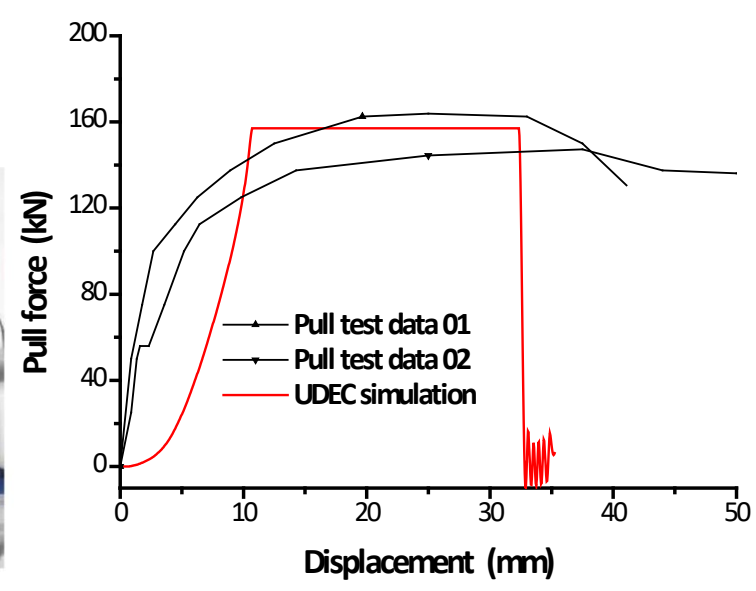

(b)

Figure 3 (a) Pull-out test rig (from Li et al. 2014) and (b) force-displacement curves obtained from the pull-out tests in both laboratory test and numerical simulation 


\section{$3 \quad$ Modelling results}

\subsection{Seismic loading versus drop testing}

There is a significant difference of the modelling results comparing seismic loading and drop testing. Figure 4 shows the force-displacement curves of the rockbolt obtained at the joint between the upper block and the lower block under both seismic loading and drop testing conditions. The frequency used in the seismic loading is $20 \mathrm{~Hz}$, which is in the range of typical corner frequencies for an event with a magnitude between 1 to 3 . The modelled rockbolt fails after the seismic loading as the displacement at the joint is larger than the deformation capacity of the rockbolt. However, the rockbolt survives the drop testing.

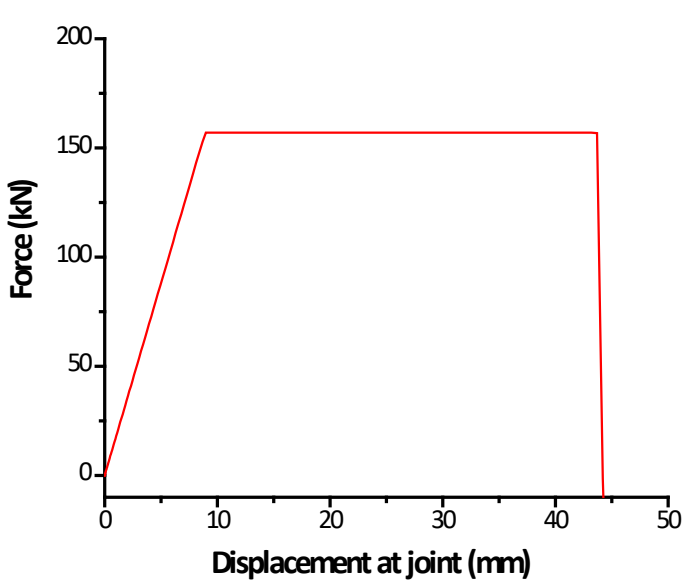

(a)

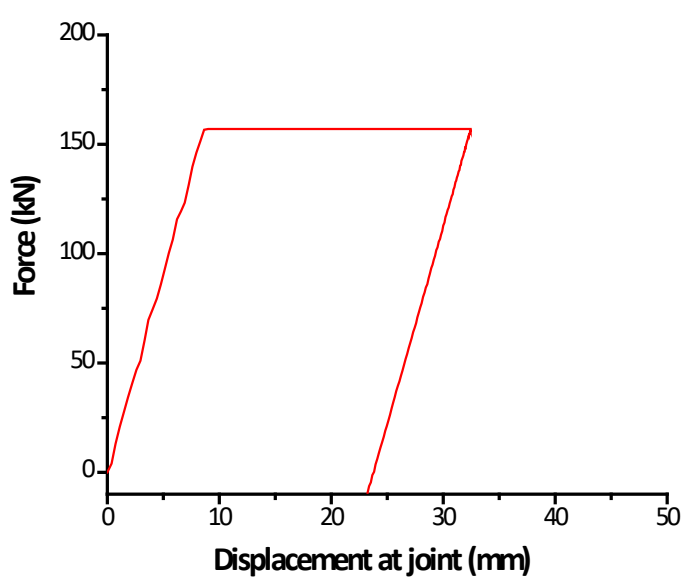

(b)

Figure 4 Force-displacement curves in the rockbolt at the joint between the upper and lower blocks under (a) seismic loading $(20 \mathrm{~Hz})$ and (b) drop testing

The velocity-time curves at the monitoring points $A$ and $B$ (Figure 5) under the seismic loading show that the ejection of the lower block occurs at $72 \mathrm{~ms}$, indicating the rockbolt has failed. By looking at the velocity curves at the monitoring points $A$ and $B$, it can be seen that the upper block has changed its moving direction and is moving upward at the time of rockbolt failure. Due to this change of movement direction, the displacement-time curves (Figure 6) indicate that the displacement difference between the upper block and the lower block becomes larger, which causes the failure of the rockbolt. For drop testing, as the upper block is stationary, the velocity at the lower block slows down due to the interaction of the rockbolt and rock blocks. The displacement in the rockbolt at the joint is generated due to the movement of the lower block alone, which is not enough to fail the bolt in this modelling scenario. Additionally, oscillation of the lower block can be observed because no damping was used in the numerical simulation. 


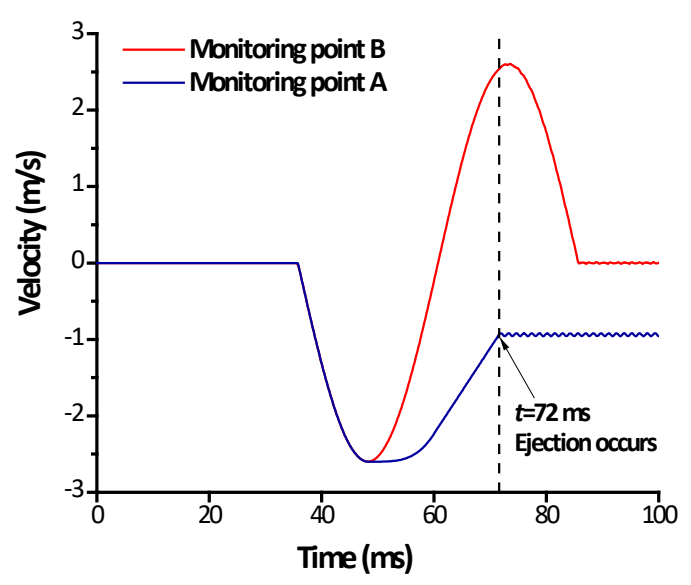

(a)

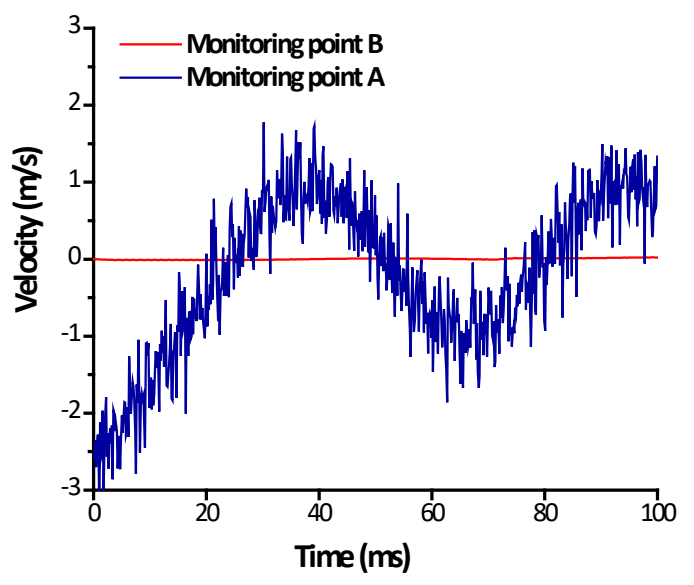

(b)

Figure 5 Velocity-time curves at monitoring points A and B under (a) seismic loading $(20 \mathrm{~Hz})$ and (b) drop testing

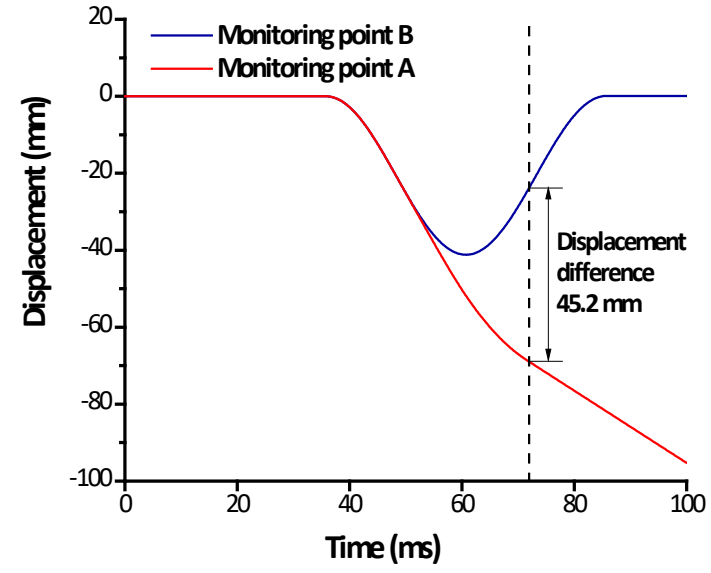

(a)

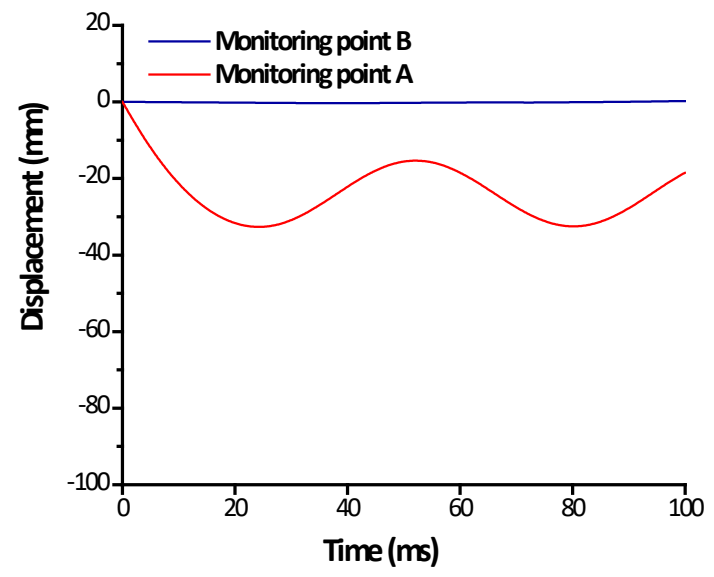

(b)

Figure 6 Displacement-time curves at monitoring points A and B under (a) seismic loading $(20 \mathrm{~Hz})$ and (b) drop testing

\subsection{Effect of loading frequency of seismic wave}

By increasing the loading frequency of the seismic wave to $200 \mathrm{~Hz}$, the rockbolt survives the seismic loading and the force-displacement curve in the rockbolt at the joint becomes closer to that of the drop test, Figure $7 \mathrm{a}$. The reason is because a higher frequency seismic wave normally creates shorter interaction time between rock blocks and rockbolt, which yields less deformation to the rockbolt. In addition, due to the high frequency of the reflected seismic wave, the upper block only has a very small movement (Figure 8 a). When the movement of the upper block changes direction, it occurs at an early stage (Figure 8b), which does not contribute to the maximum displacement difference between the upper block and the lower block.

To further check the effect of wave frequency on the rock block-rockbolt interaction, different frequencies were investigated. It is found that the displacement in the rockbolt at the joint between the upper block and the lower block reduces with the increase of the wave frequency-due to a reduction in the interaction time between rock blocks and rockbolt. When the frequency of the seismic wave increased to $625 \mathrm{~Hz}$, the force-displacement curve at the joint becomes very close to the drop test, as indicated by Figure $7 \mathrm{~b}$. 


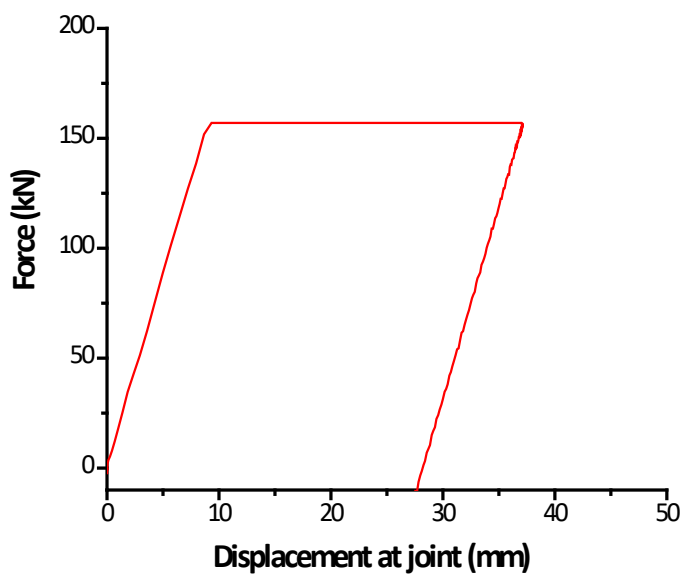

(a)

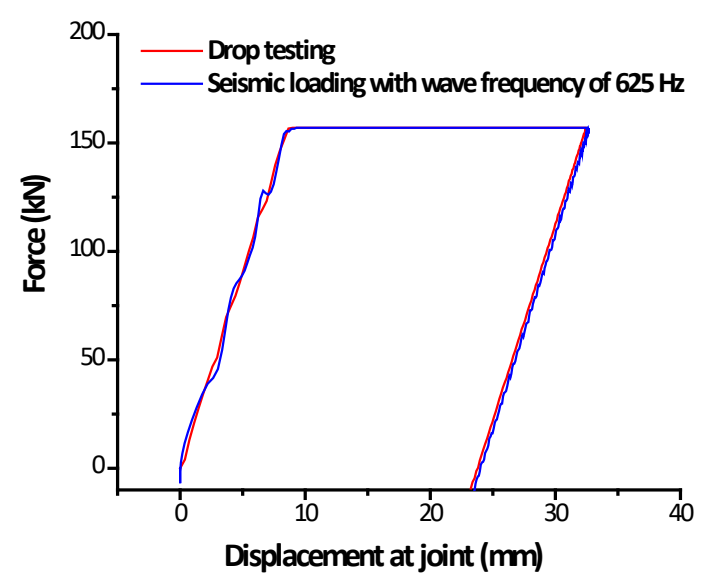

(b)

Figure 7 (a) Force-displacement curve in the rockbolt at the joint for seismic loading frequency of $200 \mathrm{~Hz}$ and (b) comparison of force-displacement curves in the rockbolt for seismic loading with wave frequency of $625 \mathrm{~Hz}$ and drop testing

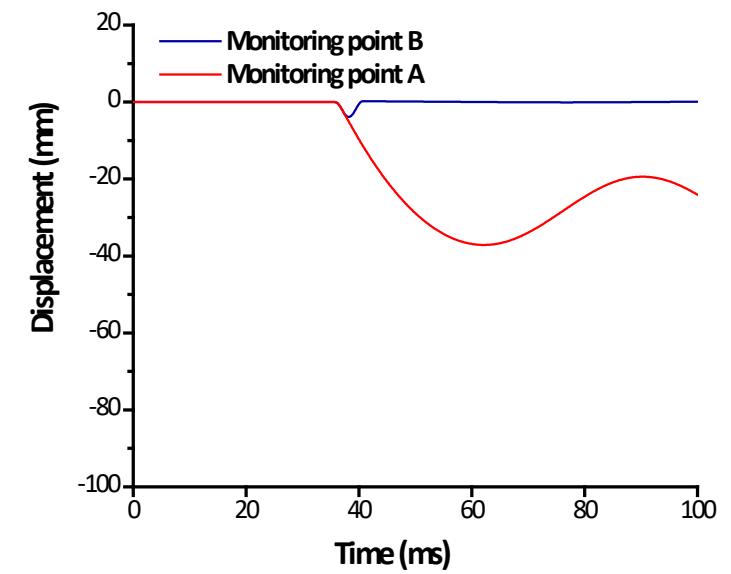

(a)

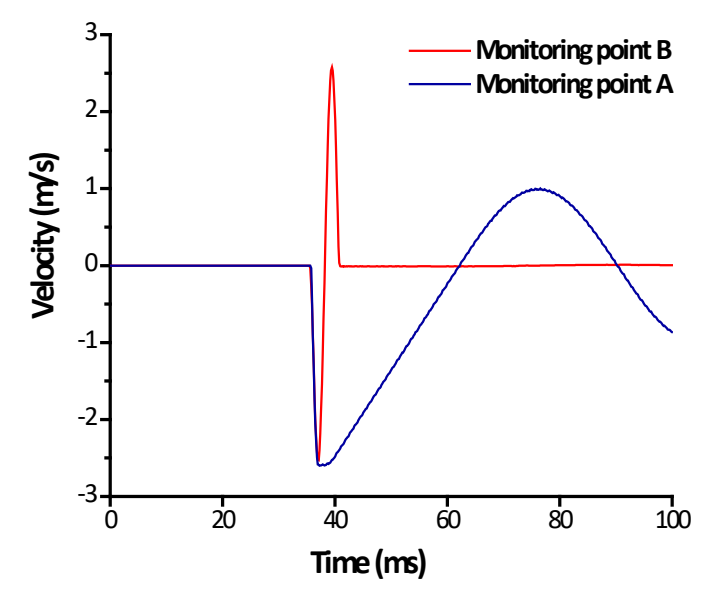

(b)

Figure 8 (a) Displacement-time curves and (b) velocity-time curves at monitoring points $A$ and $B$ for wave frequency of $200 \mathrm{~Hz}$ under seismic loading condition

\subsection{Effect of mass of drop system}

By keeping the velocity constant and equal to $2.6 \mathrm{~m} / \mathrm{s}$, the momentum ( $m v, m$ is the mass of the drop system and $v$ is the drop velocity) and the impact energy $\left(1 / 2 m v^{2}\right)$ of the drop system will increase proportionally to the increase in mass. The irreversible displacement at the joint for each drop was obtained from the numerical simulation. The critical mass of the drop system, which generated the maximum irreversible displacement at the joint, i.e. $1,470 \mathrm{~kg}$, was also obtained.

Based on the irreversible displacement created after each drop for different drop weights, it is possible to calculate the cumulative impact energy, which is necessary to break the bolt, assuming each repeated drop creates the same amount of irreversible elongation of the rockbolt. The relationship between the cumulative impact energy until the bolt fails and the applied impact energy per drop is plotted in Figure $9 \mathrm{a}$. The relationship can be fitted by a power-function curve. The rockbolt subjected to impact from a small drop weight requires more cumulative impact energy to fail than the rockbolt subjected to a larger drop weight. This agrees with the experimental results as reported by Li \& Doucet (2012) and Bosman et al. (2018). One of the reasons causing this difference is because the interaction time between the rock blocks and rockbolt used to generate irreversible displacement increases non-proportionally to the increase of the mass of the drop system or the impact energy. A larger number of impacts are needed to break the rockbolt when the 
mass of the impact system or applied impact energy is lower, which makes the cumulative impact energy used to break the bolt higher. For example (see Figure 9b), when the mass of the drop system is $1,400 \mathrm{~kg}$, the duration of the impact time is $24.14 \mathrm{~ms}$ but the elastic deformation takes only $3.68 \mathrm{~ms}$. Therefore, the actual time used to create irreversible displacement is $24.14-3.68=20.46 \mathrm{~ms}$. When the mass of the drop system is reduced to $700 \mathrm{~kg}$, the actual time used to create irreversible displacement becomes $12.80-3.68=9.12 \mathrm{~ms}$. As can be seen, the actual time used to generate irreversible displacement for $700 \mathrm{~kg}$ mass accounts for $45 \%$ of that for $1,400 \mathrm{~kg}$ mass, but the impact energy per drop of $700 \mathrm{~kg}$ mass accounts for $50 \%$ of that for $1,400 \mathrm{~kg}$ mass.

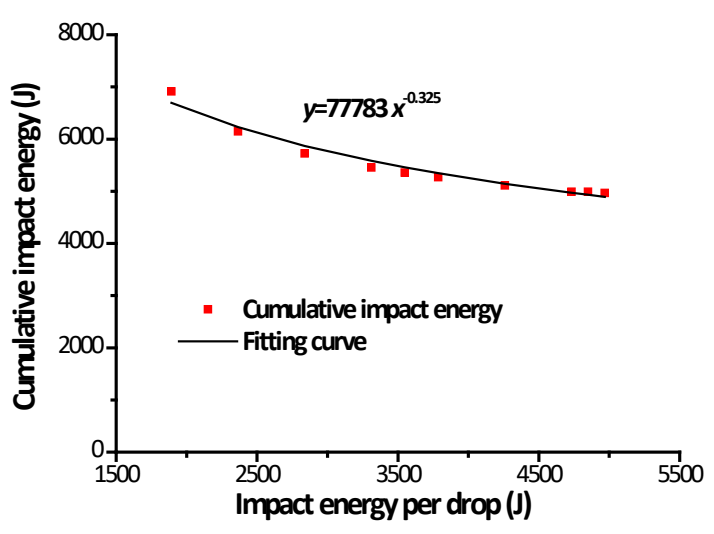

(a)

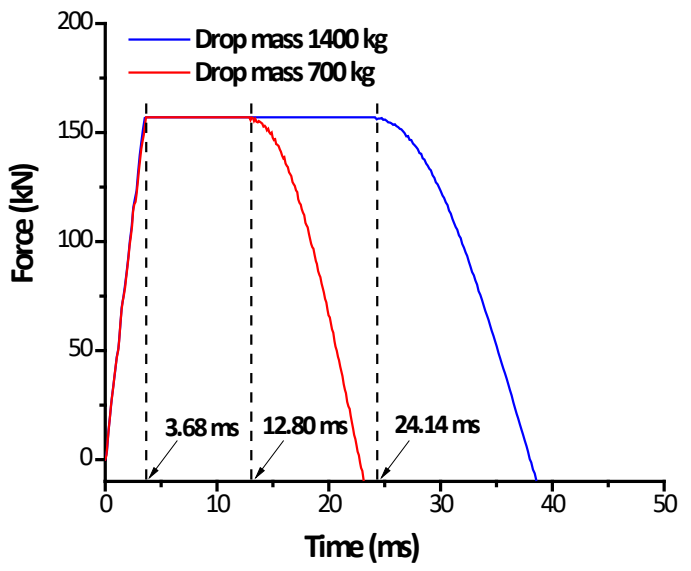

(b)

Figure 9 (a) Relationship between the cumulative impact energy and the applied impact energy per drop and (b) force-time curves for different masses of the drop system under drop testing

\section{$4 \quad$ Discussion}

\subsection{Difference between seismic loading and drop testing}

The response of the fully grouted rebar, which connects the upper and lower rock blocks, under drop test loading and seismic loading is quite different. This difference is mainly caused by the dynamic variance of their respective loading characteristics.

The seismic waves generate particle movement back and forth about their individual equilibrium positions, but the drop tests create movement mainly in one direction, i.e. downward. When a seismic wave reflects on the free surface from the seismic loading, it generates forward (downward in this analysis) movement (ejection) of the lower block but backward (upward in this analysis) movement of the upper rock block. This backward movement of the upper block plus the ejected displacement of the lower block produces a larger separation between the two blocks compared to that under drop test loading conditions, which results in the failure of the rockbolt under seismic loading condition at the same ejection velocity.

The loading frequency of the seismic wave and the drop test loading is quite different too. The loading frequency under drop test loading condition is in general much higher than the corner frequencies of typical large seismic events. With the increase of wave frequency from seismic loading, the response difference of the fully grouted rebar under drop test loading and seismic loading decreases. The reason is twofold. First, a higher frequency seismic wave normally gives a shorter interaction time between rock blocks and rockbolt. Secondly, due to higher frequency of the reflected seismic wave, the upper block undergoes a very small movement. Both result in less elongation along the rockbolt at the joint, which makes for the rockbolt to survive a higher frequency loading. In addition, by studying the effect of loading frequency of the seismic wave on rock block-rockbolt interaction, it is found that the response of the rockbolt is similar under drop testing and seismic loading at a certain loading frequency, i.e. $625 \mathrm{~Hz}$ in this modelling scenario. It can be concluded, in this particular scenario, that the predominant frequency of the drop test is equivalent to the loading frequency of $625 \mathrm{~Hz}$ of the seismic wave. By using the methodology of this simulation, the 
predominant frequency of the drop testing could be determined. In any case, the predominant frequency of the drop testing is much higher than that from an actual seismic event with the magnitude larger than one.

With any increase in the mass of the drop system, the momentum and the impact energy of the drop system increases. Based on the irreversible displacement created by each drop at different drop weights, the relationship between the cumulative impact energy until the bolt is broken and the applied impact energy per drop was obtained. Based upon these results, it can be concluded that the rockbolt, subjected to an impact from a small drop weight, requires more cumulative impact energy to fail than the rockbolt subjected to a larger drop weight. This conclusion is supported by the experimental results as reported by Li \& Doucet (2012) and Bosman et al. (2018). One of the reasons for this difference is because the interaction time between the rock blocks and rockbolt used to generate irreversible displacement increases nonproportionally to the increase of the impact energy.

When designing rock support in burst-prone ground, it is quite common to use the dynamic capacity obtained from a drop test to back-calculate the ejection velocity of a rock block, which the rockbolt is assumed to hold. Furthermore, the ejection velocity is assumed to be equal to the peak particle velocity and the corresponding maximum magnitude of an acceptable seismic event based on scaling laws is thereby determined. Caution should be exercised with this method as it might well underestimate the dynamic demand on rockbolts under real seismic loading due to the characteristics of the seismic wave as discussed previously.

\subsection{Limitations of the numerical simulation}

Many details of the drop testing were simplified in the simulation. For example, when the drop system meets the damper, the upper part of the system will not stop moving immediately in a physical test. Depending on the quality of the damper, there will likely be slight upward movement of the upper part, which could create more displacement at the joint. The actual geometry of the drop system might also affect the results.

Additionally, the actual interaction between the seismic wave and reinforced rock blocks is quite complex. When there is an actual seismic event, both P-wave and S-wave are generated and affect the interaction of rock blocks and rockbolts. Only the effects of $\mathrm{P}$-wave were studied in this simulation. Also, using a one cycle sinusoidal wave to represent the complexity of a seismic wave was an approximation but it was considered appropriate in this investigation as it has taken account of the important parameters such as waveform and wave frequency.

The parameters used for the rockbolt were calibrated by reproducing the behaviour of a fully grouted rebar in a pull-out test. The calibration was conducted under static loading condition and hence the material rate effect under dynamic loading condition was not considered which might affect the results when the loading frequency is high.

\section{Conclusion}

To obtain the energy absorption capacity of rockbolts, drop testing has been widely used. The advantage of using the drop test to investigate dynamic performance of rockbolts is that it can provide repeatable results. However, there is a need to recognise that the drop test technique is a crude simulation of an actual seismic loading mechanism.

To investigate some of the limitations, conceptual numerical models were constructed to simulate the response of a rockbolt under both drop testing and simulated seismic loading conditions using the numerical code UDEC. The numerical parameters for a fully grouted rebar were first calibrated using experimental results from the static pull-out test. For comparison purpose, the model geometry, boundary conditions and material properties were kept as similar as possible between drop testing and seismic loading - except for the dynamic loading pattern. Based on the numerical modelling results and analysis, the following conclusions are drawn:

- The response of the fully grouted rebar, which connects an ejected rock block and an adjacent massive rock block, is quite different under drop test loading and seismic loading. This difference 
is mainly caused by seismic wave characteristics from seismic loading, which generates backward (upward) movement of the adjacent rock block. This movement, together with the displacement of the ejected rock block, results in a larger separation of the two blocks compared to that of the drop test. This in turn can lead to bolt failure in the case of the seismic loading condition.

- Additionally, the loading frequency under drop test loading conditions is much higher than typical corner frequencies of large seismic events, which creates shorter interaction times between rock blocks and the rockbolt, and further smaller separation of the two blocks. With the increase of wave frequency from seismic loading, the response difference of the fully grouted rebar under drop test loading and seismic loading decreases.

- With any increase of the drop system's mass, the momentum and the impact energy increase. However, the cumulative energy required to break the rockbolt element is lower when larger mass impacts of the drop weight are applied compared to multiple small mass impacts because the interaction time between the rock blocks and rockbolt used to generate irreversible displacement increases non-proportionally to the increase of the impact energy.

- The dynamic capacity of a rockbolt obtained from a drop test is frequently used to back-calculate the ejection velocity of a rock block that the rockbolt can hold. Caution needs to be exercised with this method as it might underestimate the dynamic demand on rockbolts under actual seismic loading conditions.

- The numerical models were not designed to replicate any of the reported drop tests in detail, only their general loading conditions. Therefore, there are still limitations of the numerical simulation which need to be further improved in the future.

\section{Acknowledgement}

The authors gratefully acknowledge the financial support from the LKAB fund (Ref. No.: 2018-00005) and strategic innovation program for the Swedish Mining and Metal Producing Industry (STRIM), which is a joint investment from VINNOVA (The Swedish Governmental Agency for Innovation Systems), the Swedish Energy Agency, Formas, Lundin Mining, LKAB, Boliden and the Centre of Advanced Mining \& Metallurgy at Luleå University of Technology (Ref. No.: 2017-02228). LKAB is specially acknowledged for providing funding for the first author to conduct research in this area. Language correction by $\mathrm{Dr}$ Graham Swan is greatly appreciated.

\section{References}

Bosman, K, Cawood, M \& Berghorst, A 2018, 'Relationship between energy per impulse and dynamic capacity of a rockbolt', in CC Li, XB Li \& ZX Zhang (eds), Proceedings of Rock Dynamics - Experiments, Theories and Applications, Trondholm, Norway, pp. 379384.

Hadjigeorgiou, J \& Potvin, Y 2007, 'Overview of dynamic testing of ground support', in Y Potvin (ed.), Proceedings of the Fourth International Seminar on Deep and High Stress Mining, Australian Centre for Geomechanics, Perth, pp. 349-371.

Itasca Consulting Group 2018, UDEC-Universal Distinct Element Code (Version 6.0), User Manual, Minnesota, USA.

Li, CC \& Doucet, C 2012, 'Performance of D-bolts under dynamic loading', Rock Mechanics and Rock Engineering, vol. 45, no. 2, pp. 193-204.

Li, CC, Stjern, G \& Myrvang, A 2014, 'A review on the performance of conventional and energy-absorbing rockbolts', Journal of Rock Mechanics and Geotechnical Engineering, vol. 6, iss. 4, pp. 315-327.

Malmgren, L \& Nordlund, E 2008, 'Interaction of shotcrete with rock and rock bolts - A numerical study', International Journal of Rock Mechanics \& Mining Sciences, vol. 45, pp. 538-553.

Player, J, Thompson, A \& Villaescusa, E 2008, 'Dynamic testing of reinforcement systems', in TR Stacey \& DF Malan (eds), Proceedings of the Sixth International Symposium on Ground Support in Mining and Civil Engineering Construction, The Southern African Institute of Mining and Metallurgy, Johannesburg, pp. 597-622.

Plouffe, M, Anderson, T \& Judge, K 2008, 'Rock bolts testing under dynamic conditions at CANMET-MMSL', in TR Stacey \& DF Malan (eds), Proceedings of the Sixth International Symposium on Ground Support in Mining and Civil Engineering Construction, The Southern African Institute of Mining and Metallurgy, Johannesburg, pp. 581-596.

Sandberg, L 2017, 'New facility for testing rock reinforcement systems', News, November 2017, Swerea MEFOS AB, pp. 6-7. 
Stacey, TR 2012, 'A philosophical view on the testing of rock support for rockburst conditions', The Journal of The Southern African Institute of Mining and Metallurgy, vol. 112, pp. 703-710.

Stjern, G 1995, Practical performance of rock bolts, PhD Thesis, Norges Tekniske Høgskole (NTH) and Universitetet i Trondheim (UNiT) (Current name: The Norwegian University of Science and Technology), Trondheim, Norway.

Zhang, P, Dineva, S, Nordlund, E, Hansen-Haug, J, Woldemedhin, B, Töyrä, J, ... \& Mozaffari, S 2016, 'Establishment of experimental sites in three Swedish mines to monitor the in-situ performance of ground support systems associated with mining-induced seismicity', in E Nordlund, T Jones \& E Andreas (eds), Proceedings of the Eighth International Symposium on Ground Support in Mining and Underground Construction, Luleå University of Technology, Luleå, Sweden, $14 \mathrm{p}$. 